Illinois State University

ISU ReD: Research and eData

Theses and Dissertations

7-23-2015

\title{
The Goals Of Communicative Responses To Short-Term Worrisome Events In Close Relationships
}

Pamela Jane Steskal

Illinois State University, pamela_jane04@hotmail.com

Follow this and additional works at: https://ir.library.illinoisstate.edu/etd

Part of the Communication Commons

\section{Recommended Citation}

Steskal, Pamela Jane, "The Goals Of Communicative Responses To Short-Term Worrisome Events In Close Relationships" (2015). Theses and Dissertations. 548.

https://ir.library.illinoisstate.edu/etd/548

This Thesis is brought to you for free and open access by ISU ReD: Research and eData. It has been accepted for inclusion in Theses and Dissertations by an authorized administrator of ISU ReD: Research and eData. For more information, please contact ISUReD@ilstu.edu. 


\title{
THE GOALS OF COMMUNICATIVE RESPONSES TO
}

\section{SHORT-TERM WORRISOME EVENTS IN \\ CLOSE RELATIONSHIPS}

\author{
Pamela Jane Steskal
}

65 Pages

This paper explores communicative responses to short-term worrisome events in close relationships and goals behind the communicative responses through thematically analyzing seventy participants' responses.

KEYWORDS: Close Relationships, Communicative Goals, Emotions, Expectation Violation, Short-Term, Uncertainty, Worry 
THE GOALS OF COMMUNICATIVE RESPONSES TO

\section{SHORT-TERM WORRISOME EVENTS IN}

CLOSE RELATIONSHIPS

PAMELA JANE STESKAL

A Thesis Submitted in Partial Fulfillment of the Requirements for the Degree of

MASTER OF SCIENCE

School of Communication

ILLINOIS STATE UNIVERSITY

2016 
(C) 2016 Pamela Jane Steskal 
THE GOALS OF COMMUNICATIVE RESPONSES TO

\section{SHORT-TERM WORRISOME EVENTS IN}

CLOSE RELATIONSHIPS

PAMELA JANE STESKAL

COMMITTEE MEMBERS:

Lance R. Lippert, Chair

Stephen K. Hunt

Aimee Miller-Ott 


\section{ACKNOWLEDGMENTS}

My thesis has been a labor of love (and at times frustration), and I want to thank the people that helped me along the way. First and foremost, I want to thank Dr. Lippert for all of your support and encouragement. I know it has not always been easy but I appreciate everything you have done throughout this experience. I do not know how I would have finished this without you pushing me and guiding me. I would also like to thank Dr. Stephen Hunt and Dr. Aimee Miller-Ott for your continued flexibility and feedback during this process. Thank you, Patty Franz, for your support as well as keeping me on track. Without all of you, none of this would have been possible.

I would also like to thank my amazing friend, Laura Bruns, for her continued support and positivity. Dr. Benita Dilley encouraged me to continue my education and has always been there for me and I appreciate you and everything you have done to get me to where I am today, thank you. My family, especially my dad, has constantly had my back and encouraged me to follow my dreams and my mom, who always had faith in me. I am very lucky to have you all in my life.

Finally I want to thank my biggest champion and support, my husband, Greg. You never gave up on me, helped me through my frustrations, and have always been there for me. I appreciate you more everyday and love you dearly for helping me through my thesis process. 


\section{CONTENTS}

ACKNOWLEDGMENTS $\quad$ i

CONTENTS

CHAPTER

I. STATEMENT OF THE PROBLEM 1

II. LITERATURE REVIEW 5

Introduction $\quad 5$

Definition of Worry $\quad 6$

Emotions and Worry $\quad 9$

Expression of Worry 11

Communicative Goals in Relationships 13

Emotion Regulation $\quad 15$

$\begin{array}{ll}\text { Uncertainty and Appraisal } & 17\end{array}$

$\begin{array}{ll}\text { Expectation Violation } & 20\end{array}$

III. RESEARCH QUESTIONS 23

IV. METHODOLOGY 25

Procedures $\quad 25$

$\begin{array}{ll}\text { Participants } & 26\end{array}$

$\begin{array}{ll}\text { Data Analysis } & 27\end{array}$

V. RESULTS 32

Research Question One $\quad 32$

Research Question Two $\quad 37$

Research Question Three $\quad 40$

Research Question Four 43 
VI. DISCUSSION

Theoretical Implications $\quad 48$

Practical Implications $\quad 50$

Future Research $\quad 51$

Limitations $\quad 53$

$\begin{array}{ll}\text { Conclusion } & 53\end{array}$

REFERENCES $\quad 55$

APPENDIX A: Survey Questionnaire $\quad 62$

APPENDIX B: Recruitment Form 65 


\section{CHAPTER I}

\section{STATEMENT OF THE PROBLEM}

Worry is not a new concept but looking at short-term worry and how people communicate during events which cause short-term worry is understudied. There are times when an event occurs that causes worry. Until that worry is alleviated, individuals may enact strong emotions. It is during these times of short-term worry that people communicate in ways that may not be helpful to achieving their message goals, such as with yelling or anger. This study defines short-term worry as the negative expectations of the present moment and/or immediate future directed at someone in respect to the shortterm worry event. Past studies have not focused on how people express this type of worry or how they communicate during these times in relation to their message goals. By looking at primary emotions and motivational goals, one can see how the desire to express worry influences which primary emotions individuals experiencing the worry use, and how they communicate their worry. There is no universal response or emotion used during worrisome events, making it difficult to communicate a desired message. Being worried can lead to cognitive distractions and extreme emotional responses. This study will examine communicative responses in short-term worry situations in an effort to better understand if an individual's communicative goals are being met or if the communicative responses are actually hindering the individual's goals. Are individuals 
communicating their worry in a way that aligns with their goals, or are they simply responding to a situation without analyzing the impact of their responses?

Worrisome situations occur in everyone's lives, but very little has been done to examine how people respond to these events. Multifarious experiences cause people to experience worry. Money or health problems for example, could potentially cause worry. Likewise, a parent seeing his/her child in a moment of danger could also cause a person to worry. Further, a situation at work such as an error occurring on a project could cause short-term worry. While the word "worry" describes all of these experiences, they are disparate from each other. The first example is long-term, with coping, while the latter is short-term and happens over the short course of a few seconds, minutes or hours. The events that cause short-term worry and the responses to them can be extreme.

Furthermore, the amount of worry experienced is determined by the level of control over a situation that an individual has; the less control over the short-term worry situation, the stronger the worry and effects of the worry will be (David \& Stephan, 2013). Short-term worry is more immediate than long-term worry; the person experiencing short-term worry does not have time to think. Yelling, crying, hugging, or even physical altercations are a few examples of outcomes to these events, but the reasons these responses occur is unknown. People respond to these short-term worry induced situations without even realizing what they were worried about. As such, their responses do not necessarily correspond to the goal they hope to achieve. The communication can be misinterpreted by the intended target. For example, if a child runs into the street, the parents may yell at the child about being careless. While the goal of the parent may be to make sure the child is safe, the message being conveyed is more illustrative of anger, which may not convey 
the actual message goal effectively and can result in the child not understanding what the communication really means.

To understand short-term worry, first one must understand what worry is and what causes it. People worry about dieting, money, health, and even public speaking. People worry about themselves and other people around them, especially those who are close relations to each other (parents, siblings, close friends, co-workers, and romantic partners). Romantic relationships especially involve situations that can create a great deal of worry and people worry about the health of their romantic partner and the status of the relationship. Uncertainty about the relationship can cause worry as well. A romantic partner not answering his/her phone may provoke thoughts like, "is he/she injured, just being negligent, or cheating?" Jumping to conclusions based on fact or inference can lead to worry in these situations. The uncertainty causes worry and until that worry subsides, emotional turmoil can ensue.

The lives of those closest to us hold intrinsic value in our day-to-day existence, and while it can never be known exactly what occurs at every second of every day for our romantic partners, parents, close friends, or siblings; the desire to know that they are okay is ever-present. Yet, repetitive and intrusive requests for such knowledge are not ideal for the welfare of either side of a relationship. Inquiries can come by way of a telephone call, a text message, a web-cam chat, an email, a face-to-face encounter, or, less often, a written letter. Sometimes people reach out and attempt to initiate this communication, and sometimes they expect the other person to reach out to communicate with them. When communication is absent or is refused by one of the people involved, worry can occur. This study will focus on understanding how people in close relationships 
communicate during short-term worrisome events and what these short-term worrisome events look like. Subsequently, by examining the message structure the person experiencing the short-term worry chooses with which to convey his/her message, the study will also attempt to determine the individual's goals during these short-term worry situations. Further, the study will examine if an individual's goals are being achieved through this communication. This information may help provide insight into applying appropriate responses to worrisome events.

Previous literature has explored a variety of issues related to worry ranging from psychological studies of emotional worry and rumination to the study of anxiety and other related mental illnesses. Others have studied and produced theories about the way individuals communicate their expectations and how that relates to and causes worry in various types of interpersonal relationships. This study builds upon the previous literature and identify what constitutes a short-term worrisome event, which is unknown. Gaining a better perspective of what a short-term worrisome event are will help analyze how individuals communicate in those situations. From there one can look at whether or not communicative goals are being achieved through the communication of worry. 


\section{CHAPTER II \\ LITERATURE REVIEW}

\section{Introduction}

While short-term worry has not yet been directly studied, there is a great deal of previous literature on a variety of topics that are related to short-term worry. In this study, I look at a wide range of previous research to help frame the themes and codes used in the analysis of the responses obtained. Several studies in the field of psychology have looked at various types of worry that humans experience, and how that worry impacts people's lives. Those studies explored the way individuals reacted in various situations involving worry and further, the outcome of those responses and how they relate to anxiety and rumination. This study expects to find that short-term worrisome situations tend to elicit strong emotional responses. There are several studies that have focused on the way worry and emotion are tied together, and how that connection impacts the way individuals communicate during worrisome situations. Scholars have also looked at the goals that individuals have while dealing with worry. These goals are related to both the type of relationship that the individual is involved, and also the situation that occurred to cause them to experience worry. Appraisal and regulation theory, uncertainty, and expectation violation are three themes that will be further reviewed to provide a framework for the study. Appraisal and regulation theory provide insight into how individuals process events than can cause worry. Appraisal and regulation also look at the goals a person may 
have during a particular event. These theories help to frame the themes and codes found Burkovec, Robinson, Pruzinsky \& Dupree have investigated worry in the long-term sense and addressed worry over a period of time and constant daily negative thoughts instead of short-term worry that has a more set start and stop period. Arguably, after the incident is over, the worry dissipates in a short-term time frame.

\section{Definition of Worry}

A popular definition of worry in literature comes from the scholars who developed the first worry measure entitled the Penn State Worry Questionnaire (PSWQ), "Worry is a chain of thoughts and images, negatively affect-laden and relatively uncontrollable," (Borukovec et al, 1983, p.10). This definition stems from the study of clinical patients with pathological worry. Psychologists in the past 15-20 years, however, have made efforts to study worry outside the context of pathological illness. Tallis, Eyesneck \& Matthews (1992) sought to understand the difference between normal and pathological worry by creating a measurement that attempted to capture the typical sources of satisfaction in everyday life. The measure, entitled The Worry Domains Questionnaire, examines the following sources of worry: relationships, financial status, future, work competence, socio-political, and confidence. These sources were identified as the most common and relevant day-to-day areas of worry for individuals without pathological worry (Tallis et al., 1992, p. 168). Tallis et al. (1992) then identified the intensity and length to which worry is generated from each source. They found that "worry might be usefully construed as a response to the violation of goals associated with these 'sources'," (Tallis et al., 1992, p. 168). Davey (1993) compared the Penn State Worry Questionnaire and the Worry Domains Questionnaire and found them to measure 
worry differently, especially regarding task-oriented constructive worrying. The Worry Domains Questionnaire measure was considered more effective for measuring taskoriented constructive worrying than the Penn State Worry Questionnaire (Davey, 1993).

These earlier studies of worry have helped recognize the need for further research related to worry and identified some important concepts that are related to worry; such as negative thoughts violation of goals. It also identifies some sources of worry, relationships and financial status, which may be relevant to short-term worrisome events. Along with pathological worry, rumination is another term often linked with worry.

When researching worry, psychologists have often studied its effect in concurrence with rumination. Rumination refers to the constant negative thinking of past events. Psychologists differ on the question of whether one can occur without the other, although many distinctions exist in the function of each process. Worry has been identified as the defining feature for General Anxiety Disorder while rumination is more consistently found in depression (Tallis et al., 1992). In addition, rumination is linked specifically to several pathological illnesses (including General Anxiety Disorder), whereas worry is often studied exclusively with General Anxiety Disorder. General Anxiety Disorder is conventionally defined as chronic worry (Meyer, Miller, Metzger \& Borkovec, 1990). Psychologists have even shown an ability to distinguish between rumination and worry (Goring \& Papageorgiou, 2008) making the study of worry as an individual factor a relevant endeavor. Goring \& Papageorgiou (2008) used a factor analysis in applying the Ruminative Response Scale and the Penn State Worry Questionnaire to find out if participants were able to discriminate between these two factors. Their findings demonstrated that the construct of worry can be differentiated 
from rumination by participants. In their study participants were able to identify between the tendencies to worry versus dwelling on negative feelings. This further supports the idea that worry can be studied by itself and not just in relationship to rumination.

Perhaps one of the most prominent reasons worry has not been closely examined in a distinct situational context is the abundant area of mental illness research. The importance of understanding mental illness can never receive too much attention; yet, focus on present tense worry has repeatedly been skipped in previous research. Psychologists attempt to focus on patients with mental illness on the here and now, as to facilitate individual cognitive and physical processes. This strategy has been proven to be a positive way to move forward without the cognitive and emotional baggage of past and future possibilities. Worry is elicited in response to anticipated threats. What is remarkable, however, is that when individuals described their worrying process, they were poor at generating successful solutions or effective coping responses, but very good at defining possible problems.

Anxiety is another part of the human experience that overlaps but is distinct from worry. While Burkovec et al. (1983) contested that worry and anxiety be analyzed separately, the idea was considered ineffectual because the two concepts were usually tied together as one in literature. As mentioned before, General Anxiety Disorder is conventionally identified as chronic worry. Another study by Stober and Muijs (2001) reanalyzed data from Reisenzein and Spielhofer (1994) that attempted to find differences in anxiety and worry in participant responses. The original data examined situational appraisal by asking participants to explain an instance of worry and an anxiety instance. Original results, however, were not presented in a way that allowed the reader to 
understand precise differences between worry and anxiety (Stober \& Muijs, 2001). While many of the reactions between worry and anxiety were similar, several were revealed to be markedly different. Worry situations were more often "associated with positive self evaluations, positive social-relationship appraisals, feelings of closeness, superiority, importance and focus," (Stober \& Muijs, 2001. p. 373). In addition, participants tended to focus their worry on others while self-focus was more prominent in anxiety situations (Stober \& Muijs, 2001). Stober and Muijs (2001) then replicated the study to discover inconsistencies in situational appraisals. Finally, after adjusting for relevant situational appraisals, Stober and Muijs (2001) performed a third study that gathered three responses from each participant, resulting in twice as much empirical data than Reisenzeing and Spielhofer (1994). Results supported Reisenzeing and Spielhofer's (1994) findings. Participants tended to have a goal in-mind in worry situations and focused their worry on others half of the time while anxiety appraisals often did not include a goal and were selffocused.

Building upon the definition of worry from previous literature the next section will explore how emotions impact the way that individuals communicate while experiencing worry.

\section{Emotions and Worry}

This study expects to find that emotion plays an important role in the communication of worry in short-term situations. According to Mancillias, Wilmot, and Metts (2009) emotion is "a relatively brief state of arousal, which has positive or negative valence and which activates the body to respond in some way" (p. 4). The primary emotions are happiness, sadness, disgust, fear, and anger. These are described as being innate and a 
reflexive gesture. Affective states are a larger concept that includes an emotion. For example, loneliness is considered an affective state because it might include sadness or fear at different times. Worry, then, could be categorized as a secondary emotion or affective state. Secondary emotions differ from primary emotions in three different ways. First, secondary emotions are learned from cultural and societal norms. These are for more social reasons than survival like primary emotions. How individuals express them are "embedded with the norms and languages of groups, societies, and cultures" (Mancillias et al. 2009). Next, primary emotions have facial expressions that are universally recognized while secondary emotions rely on a mix of the primary emotions to express. Therefore more is needed to express these emotions, such as nonverbal and verbal cues. The last differential characteristic is how an individual expresses secondary emotions. There is no universal display for worry; it requires other emotions to support it. When expressing worry, facial expressions lack the ability to communicate worry. Instead anger, sadness, or fear can be used to show worry. Worry relies on primary emotions or a blend of other emotions for full expression. There is an overlap in emotions for secondary emotions. For example, jealousy might include the emotions sadness, anger, or disgust (Mancillas et al. 2009). By using this evaluation of secondary emotions, this study can make the argument that worry is a secondary emotion. According to the criteria, worry is a secondary emotion whether it is long-term or short-term. As stated before, people worry about money, health, dieting, and various other reasons. Some related to cultural norms and societal norms. For example, people worry about losing weight and improving their image — self-image being a social construct. Short-term worry, such as not being able to contact someone, is also socially 
constructed and has become far more prevalent due to modern technological advances that allow immediate communication, essentially, at all times.

Secondary emotions are complex because they are comprised of multiple emotions, and the one that is most prominent at the time will influence how the secondary emotion is expressed. For example, if a person is worried about a relationship, the worrier will try to reduce the uncertainty or alleviate the worry by expressing it to the person if the strongest emotion of worry is fear. If the emotion is sadness, the worrier may try to express that emotion or withdraw from it. Further, if the worrier's prominent emotion is anger, he/she may lash out or engage in more aggressive communicative behaviors to express the worry. If the person apologizes and gives an explanation, the emotion will be minimized. If the person who an individual was worrying about does make contact, that fear could be transformed to anger if that person places blame on the worrier which would increase the emotional expression.

Understanding the role emotions play during worrisome events provides an insight into the different ways people communicate and express themselves while worrying, which the next section will address in more depth.

\section{Expression of Worry}

The expression of worry occurs through its presence as not just a process, but an emotion. Emotional expression of worry has been defined as the ability or inability to control negative feelings (Ruscio \& Borkovec, 2004). This indicates that emotions are an inseparable result of worry. The emotional response type that most aligns itself with worry may be the fear construct (McCaul \& Goetz, 2008). McCaul and Goetz also mention that worry is activated on a less recurring basis and does not evoke as strong as a 
response as fear. In terms of how the words are used in social contexts, semantic scholar Johnston \& Warkentin (2010) identifies worry as a socially acceptable substitution for fear. The connection between the two constructs is more complex than this affective state. While worry is similar to fear, other factors can play a role into worry versus fear, such as fear is caused by a known threat whereas worry can be caused from the unknown. Further, when people experience worry, they tend to have different reactions based on how much control over the situation they have. In situations where individuals have control of the events, they tend to feel they are worrying in a constructive way, however, in situations where the event is out of the individual's control the worry felt is not related to problem solving or strategy (David \& Stephan, 2013). If the worry is in a person's control, he/she may express their worry differently than when it is out of his/her control. How a person expresses his/her worry and the way he/she communicates it and to whom are also important when studying how people communicate in short-term worrisome events.

"Emotion expression refers to the outward manifestations of emotional states" (Planalp, Metts \& Tracy. 2009, p. 2). Expressing an emotion to another person leads to a response from that person which can be attitudinal or behavioral (Metts \& Planalp, 2002). When people express their worry to another person, they are letting the other person know how they are feeling and expect some feedback. The amount of emotional release the worrier expresses is also important in the response of the other person. Emotion regulation is the experience that a person goes through when deciding how much emotion to show or to not show (Gross, 1998). When conveying worry, how the individual expresses and regulates worry influences the feedback from the other person or target. In an intense worry situation, anger can be the primary emotion expressed but if it is not regulated, the target of worry 
could respond negatively and the expression would be ineffective in achieving the relational or communicative goal or getting a desired result.

There are also therapeutic reasons why emotion expression regulation occur or do not occur. Very emotional experiences are hard to forget and difficult to regulate. Also the effort in trying to suppress the emotion puts it into the forefront of a person's mind and keeps a person thinking about the emotion (Richards \& Gross, 2000). This may lead to the opposite of regulating the emotion through "post suppression rebound" (Wegner, 1992, p. 205). The person will think of the emotion, and try to suppress it in different ways, but is unsuccessful so the emotion is continually on his/her mind. On the other hand, expressing an emotion can gain further insights in why the person felt the emotion and move on from the event (Pennebaker, 1997).

The previous sections have addressed the various ways that people experience worry, and how their emotions can impact the way that they act and communicate during worrisome events. The following sections will reflect on that information while examining how people communicate in close relationships and while worrying, and how regulation theory, appraisal theory and expectation violation are related to communication in close relationships and the communicative goals of people in those relationships while they are experiencing short-term worry.

\section{Communicative Goals in Relationships}

Positive outcomes of feeling and expressing worry are discussed in several studies. For example, some people express worry as a method to alert someone to danger, such as a parent yelling at a child for running into the street; however, this method may not always achieve the communicative goal of the individual (Parkinson \& Simons, 2012). The parent 
may yell at the child, and while the communicative goal of the parent is to make the child aware that they were doing something dangerous, the way they communicate during that short-term worrisome event may not deliver the message clearly. Davey (1993) found that the activation of worry helps motivate a person to cope with and/or eliminate the source of worry; the parent yelling may get the child out of the street quickly and may make the parent feel as if they have regained control of the situation for example. The active aspect of worry is identified as more constructive than rumination (Davey, 1993; Papageorgiou \& Wells, 1999; 2003). Papageorgiou and Wells (1999; 2003) examined both clinical and non-clinical patients and determined that rumination produced far fewer positive effects compared to worry. Participants' worrisome thoughts enabled them to construct better verbal content, greater compulsion to act, more effort to problem solve and more confidence in problemsolving than their ruminative thoughts, which were rated as more past-oriented. These participants were also more likely to act on the source of the problem. While long-term negative thoughts can be have negative effects on a person, worry can help a person deal with his/her anxiety and expressing it can help relieve worry or at least, minimize it. Communicating worry is better than internally ruminating about it. Ruscio and Borkovec, (2004) found that when comparing those with and without General Anxiety Disorder, however, the participant's ability to complete a task was diminished when suffering from General Anxiety Disorder. This was attributed to the thoughts of negative feelings that dominated the cognition of those with General Anxiety Disorder. (Ruscio \& Borkovec, 2004). The inability to get past the negative thoughts impaired the person. This study will look at a more active role from the participants in how they respond to worry, but in a short- 
term context; and how the way people respond to short-term worry impacted their relationships.

\section{Emotion Regulation}

Regulating one's emotions can be linked to appraisal theory (Gross, 1998). This theory maintains that two types of emotion regulation are cognitive reappraisal and suppression. Cognitive appraisal is how the person feeling the emotion interprets it in a positive light, while suppression is concealing the emotional signs (Richards \& Gross, 2000). Richard and Gross "speculate that positive illusions and benign attributions shape the appraisal process in relationally productive ways" (p. 415). During the different stages of appraisal, the true emotion can be exaggerated or suppressed and also the entire emotional experience can be redefined (Gross, 1998). Appraisal theory has three different stages. The initial stage is called the primary appraisal, and it reflects the initial response to what is occurring and if it is significant. Then the person has to decide if what is occurring is negative or positive and that leads to first emotional responses. The primary appraisal is quickly changed to the secondary appraisal. This includes more cognitive thinking about the situation as more knowledge is gained. During the secondary appraisal, meaning of the initial emotion is examined and adjusted (Mancillias et al., 2009). If the initial reaction was due to overreactions or social norms, remedial actions will follow. Machillias et al. (2009) also state that "although social conventions operate in many contexts, interpretations of the same environmental cues can be quite different based on personality and past experience" (p. 7). The third appraisal is called reappraisal. Cognitive thought is used to examine the secondary appraisal at a later time. This allows for a more cognitive process of the emotion (Mancillias, Wilmont, \& Metts, 2009). 
After the first appraisal and emotion, during the second appraisal, the emotion is not expressed for just the person with the emotion but also to the person who caused the emotion. This emotion can be used to send a message to the other person to continue or discontinue a behavior. Expressing the emotion also allows for the person with the emotion to deal with the emotion by alleviating it or to keep it going. Mancillias et al. (2009) make two assumptions to explain this; "The first assumption is that behaviors or messages of the other person or persons are the cause of our emotion and that communicating it will somehow influence the person to change negative behaviors or to continue positive behaviors. The second assumption is that our own behaviors or messages are the cause of our emotion and responses from others are necessary to reduce or sustain the emotion." (p. 16).

As the literature previously stated, there is a strong rationale for worry as a secondary emotion and the different primary emotions that could be used to express worry. Appraisal theory explains why the emotion and expression change over a course of time. Two assumptions are made as to the main motivations for expressing an emotion; however, other goals of the worrier could change how the secondary emotion, worry, is expressed.

When threatening information is presented to an individual, worry is triggered (Matthews, 1990). Threatening information could cause an individual to worry about the relationship as a whole. It could also be argued that the lack of threatening information or any information at all could also lead to worry. This lack of information could lead to high anxiety and stronger expressions of worry. In these cases people worry as a comfort seeking function (Parkinson \& Simons 2012). Though in these cases this type of worry results in the opposite result, only making the person feel even worse about the situation 
and not helping to find a solution to the situation (Parkinson \& Simons 2012). Because of this, relational outcomes do not always align with the individual's intended communicative goals.

\section{Uncertainty and Appraisal}

A study performed by Davey (1993) makes the connection between people with high long-term worry and strong information seeking-tendencies. People who experience a lot of worry tend to do things in an effort to find out information to alleviate the worry they are feeling. This could include asking people information about the topic of the worry, having a savings account, or having more frequent health checks. This can relate to the current study because those that worry will express their worry and find information as to why the person caused the worry. Uncertainty is a major factor in shortterm worry and people with strong information-seeking tendencies may have different ways to achieve their goals. When the person of worry does not explain and relieve the worry, uncertainty will grow with the worrier (Knobloch \& Soloman, 2005). Here again, if the individual experiencing worry feels like the situation is out of his/her control, the feeling of worry will continue to grow (David \& Stefan, 2013). Further, in worrisome situations, people will generally feel that the worry they feel can be used constructively (David \& Stefan, 2013). However, in short-term worrisome situations, worry often leads to a situation in which the person experiencing worry does not have control of the situation, and the reaction therefore may not be a constructive tool for conveying the desired message.

These information-seeking tendencies sprout from uncertainty. Uncertainty, which is a state of unknowing, is another aspect of worry that plays an important role in 
the way individuals express themselves and communicate, especially in short-term worrisome situations. Smith and Ellsworth (1985) found that- "uncertainty appraisals are characterized by feelings of uncertainty, lack of understanding of what is happening, and not feeling certain about what will happen next. Emotions such as anger, disgust, happiness, and contentment are associated with certainty; while hope, surprise, worry, fear, and sadness are associated with uncertainty" (p. 835).

Cheng, Kuan, Li \& Ken (2010) also makes a correlation between the feelings of uncertainty that would lead to more problem-focused coping whereas conversely, emotions associated with certainty would lead to more emotion-focused coping. Problemfocused coping was seen to be more positively related to solving the problem instead of emotion-focused coping which is more related to regulating distressing emotions or to minimize the experienced emotions by other means such as distractions or avoidance. There are many different ways to experience uncertainty: uncertainty of relationship status, uncertainty of the well-being of the other in a close relationship, uncertainty of the feelings of the person causing the worry.

Aune (2006) studied how various levels of relationship certainty impacts emotional expression in romantic relationships. During the early stages of a romantic relationship less emotional expression is seen due to the uncertainty of the relationship. As the relationship progresses and matures, there is more certainty between the partners which leads to a larger degree of emotional expression; this is because the partners feel the relationship is strong enough to withstand more expressive emotions. Clark and Finkel (2005) had similar findings and reported "the nature of the relationship a person perceives he or she has with another person to whom emotion might be expressed is a 
potent determinant of whether that person will express or suppress emotion." Therefore, in order for the person in the romantic relationship to be willing to show greater emotion, there has to be certainty in the relationship and confidence in the partner to accept a greater range of emotion. There was also a higher correlation between certainty in a relationship to express more negative emotions than with uncertainty in a relationship (Aune, 2006). Worry, as a result of uncertainty, can repress emotional expression in relationships and also manifest in the expression of fear and jealousy.

Jealousy situations also can lead to uncertainty and potentially short-term worry about a relationship. Booth and Kennedy (2011) examined how jealousy led to uncertainty in married and dating couples. They found "Generally, married people were more concerned with relational attention diverted to non-romantic alternatives, whereas dating partners were more jealous of the potential threat of romantic competition" (p.272). Similar to Aune (2006) this study finds that as a relationship develops and matures, the partners feel less uncertainty about the actual relationship, whereas newer relationships feel uncertainty about the stability of the actual relationship. Dainton \& Aylor (2001) also had similar findings. They ascertained that when there is a strong commitment, people are more confident in their relationship. However, in some cases an individual may not want to actually work to reduce uncertainty but will cope or manage his or her uncertainty. (Brashers, Neidig, Haas, Dobbs, Cardillo \& Russel. 2000) For example, if a person feels their partner is cheating, he or she may actually choose to deal with the uncertainty internally or through avoidance due to the fear of the results that may happen (such as the relationship ending). Jang, Yoo \& Tian (2011) looked at how people act in relationships following an event that leads to increased uncertainty; they found that as uncertainty increases, people tend to use avoidance to cope 
with the uncertainty that they are experiencing. These ideas can be applied to a short-term worrisome event as well because like jealousy, situations, can lead to high levels of uncertainty and influence how a person may react based on the level of uncertainty. Relationship length and security can also relate to short-term worrisome events and what people worry about. In a strong commitment relationship, people may tend to focus more on health or finances, while newer relationships may worry more about relationship status. Relationship length and strength of commitment can also factor into expectations a person has in a relationship and how people communicate his/her worry when those expectations are violated.

\section{Expectation Violation}

Expectation violation is a theory that can be examined when discussing short-term worry and message goals. When an individual's expectations are violated by someone he/she is in a close relationship with, short-term worry can occur. Expectancy violation theory assumes that individuals form expectations for communicative interactions with others, and when those expectations are violated individuals think more about the situation and become more emotional (Burgoon \& Hale, 1988; Burgoon \& Jones, 1976). After a violation occurs, the individual starts to think, negatively or positively, about the situation in relation to the situation that occurred, and also about the relationship itself (Afifi \& Metts, 1998). The way an individual views the violation of expectation also directly relates to how they communicate with the violator (Chiles \& Roloff, 2014). During short-term worrisome events an individual may feel the need to respond based on his/her expectations and how he/she feels they were violated. Individuals in close relationships have certain expectations of one another based on a variety of relational 
behavior and social norms. These expectations "can facilitate relational quality when they promote positive relational behaviors that can be realistically enacted; however, when expectations are so unrealistically high that one's partner is incapable of meeting them, relational harm may result" (Wright \& Roloff, 2015, p.15). In certain situations in close relationships, the violation of relational expectations can result in short-term worry. For example, if a person's significant other is always punctual but then one night the significant other is running late and does not communicate the reason why short-term worry may occur due to the expectation violation. Burgoon (1995) stated that expectations can be influenced by context situations, or by the relationship between communicators (Burgoon, 1995). In this example, when the partner does not meet the expectation of the other, it can signal to the other partner that he/she does not value the relationship (Afifi \& Metts, 1998). Further, in this example, the concerned person can also experience short-term worry, wondering if the person was involved in accident or otherwise hurt. When the person finally arrives, the concerned person may communicate in ways that are inconsistent with their message goals.

The way people structure their messages is related to the way that they process various situations and relate them to the current event. Eagly \& Chaiken (1995) define two ways in which people process information and structure messages: Systematic and Heuristic. Systematic processing is "conceptualized as comprehensive and careful consideration of message content" whereas heuristic processing "relies on simple decision rules to make a judgment rather than to scrutinize the situation" (Yun, 2005, p.525). Depending on the short-term worry situation either of these processing methods could be present. In the example of a significant other being late, systematic processing may occur 
the longer the person is left waiting, whereas if a parent were to witness a child running into the street heuristic processing will be used instead.

Short-term worry may not have been directly studied before, but previous research does explore many important aspects of worry that can be applied to short-term worrisome events, especially in close relationships. An individual's communicative goals during these events can be shaped by a number of different factors, whether it is due to uncertainty or if a violation of the relationship is perceived, people communicate during these events in a variety of ways. By understanding the literature on worry in general this study will analyze a survey presented in the next chapter based on the following research questions. 


\section{CHAPTER III \\ RESEARCH QUESTIONS}

In order to establish a basic foundation for short-term worrisome events, four research questions guided the study. Discovering what people think that short-term worrisome events are is the first step to further develop this subject. However, it is important to understand what a short-term worrisome event is before we can begin to uncover more about short-term worrisome expression.

RQ1: What events lead to short-term worry for participants in a close relationship?

After identifying a short-term worrisome event, it is crucial to see how a person would communicate his/her short-term worry. Would he/she communicate it to the person that caused the worry or to a third-party and how would she/she communicate this short-term worry she/she experienced? The communicative responses to a short-term worrisome event will help to gain a broader understanding of short-term worrisome events.

RQ2: What are the types of reactions/responses people employ to express their short-term worry?

The goals behind the communicative response are equally important to further study short-term worry. While a person may react quickly to a short-term worrisome 
event, the goals behind the reaction are another area unexplored even though knowing the goals behind the expression of short-term worry can people identify better ways to react/respond to a short-term worrisome event. Thus the following question was advanced:

RQ3: What, if any, types of relational goals do participants employ when deciding whether and how to express their short-term worry?

Finally, learning about what the person hoped to achieve by expressing their short-term worry will help to evaluate the effectiveness of his/her communication. Since these events occur in a limited small time frame, the reactions may have less time to formulate their responses. By truly reflecting on the results of different reactions, this study hopes to develop better ways to communicate short-term worry.

RQ4: How, if at all, do participants feel like their particular responses to the worrisome event help achieve their goals?

By exploring these four research questions, a foundation will be formed of what short-term worrisome events look like and how people communicate their short-term worry. It will also identify relational goals from the person that experienced the shortterm worry and whether or not his/her communicated response to the short-term worrisome event helped achieve the goal he/she had in mind. 


\section{CHAPTER IV}

\section{METHODOLOGY}

The previous chapter outlined four different research questions that need to be answered in order to make further progress into short-term worrisome events and how it is communicated. The current chapter will describe the procedure used to examine this as well as a description of the participants. Finally, this chapter will explain thematic analysis in relationship to how the data was analyzed.

\section{Procedures}

Due to the newness of this subject, a survey was formulated based on the research questions to start gathering information on short-term worrisome events. The online survey asked participants to first describe in writing a short-term worrisome event involving someone in a close relationship. Then the participants were asked to identify the person in the short-term worrisome event and the type of relationship (friend, family, significant other, or spouse) as well as the length of the relationship. Finally the participants were asked to describe how, if at all, he/she responded to the event and the goal behind their response to the situation. Then the participant was asked to identify whether or not he/she believed that his/her goal was achieved by the way he/she did or did not responded or communicated. 
The participants were also asked to describe the degree of worry on a scale of one to five, one indicating the least amount of worry and five indicating the most amount of worry. Then participants were told to describe the reaction or response of the person he/she communicated his/her worry to and also what impact the event had on the relationship. Finally the participants were asked to describe how the event made him/her feel as well as if the event helped alleviate his/her worries. The last portion of the survey asked various demographic questions.

\section{Participants}

This survey was completed by 70 individuals, 19 males and 51 females, who identify as being in a close relationship (significant other, friend, family, or spouse). Participants took an online survey consisting mostly of open-ended interview questions hosted on SelectSurvey that were recruited through online social networks (such as Facebook) as well as email at a University and workplace. Sixteen participants were between 17 and 21 years old, 15 were from 22 to 25,14 were between 26 and 30, five were from 31 to 35 , seven were ages 36 to 40 , one was between 41 and 45, two from 46 to 50, two between 51 and 55, four were between 56 and 60, and four were between 60 and 70. Sixty-four of the participants were white/non-Hispanic, three Hispanic, one Asian or Pacific Islander, one black/non-Hispanic, and two other. Three of the participants had been in the relationship in which they experienced the short-term worrisome event less than a year, ten for one-three years, 14 from three-10 years, and forty-three for over ten years. The worrisome relationships included 36 from family members, 17 from friends, 11 from significant others, and six from the spouse. 


\section{Data Analysis}

In this study, the researcher used thematic analysis to evaluate the data collected through the online questionnaire to gain an understanding of how individuals react to short-term worrisome events and how their communicative goals are expressed and whether or not they are achieved by the way they communicated their worry. Thematic analysis was used to identify and analyze themes within the data set (Braun \& Clarke, 2006). By looking at patterns that presented themselves in the data it was possible through thematic analysis to describe the data in a detailed way and interpret the data in a way that will identify the most common way that individuals reacted and communicated during short-term worrisome events. Further, using thematic analysis made it possible to explore the various themes as they emerged from the data. Other forms of qualitative analysis such as discourse analysis, grounded theory, or interpretative phenomenological analysis seek to generate a theory of phenomena that is grounded in that data, whereas thematic analysis searches the data for themes that can help to explain the phenomena being studied (Braun \& Clarke, 2006). Since there is not a theory directly linked to the data in this study, finding emerging themes in the data using Braun and Clarke's thematic analysis was imperative to understand short-term worrisome events and the communicative responses to these events to allow for future research.

Using inductive analysis for the purpose of identifying and coding the data helped explore emerging themes in this study. Inductive analysis is the process of coding data without trying to fit it into pre-existing coding frames or analytical preconceptions (Braun \& Clarke, 2006.). The coding was data driven, and allowed for themes to emerge naturally from the data set. Inductive analysis does not base any coding on previous 
research but rather frames its own codes based on the data set. In this study this allowed for codes to be formed strictly based on individuals reacting to short-term worrisome events. This study used a six phase guide presented in Braun and Clarke's piece on thematic analysis to analyze the collected data.

Phase one of the analysis involved learning as much about the data as possible. This was accomplished by reading and re-reading the data and in doing so searching and identifying meanings and patters that are present. During this phase notes were taken on any themes or patters that started to emerge. These notes were then used in phase two. Phase two involved the creation of codes based on the information and understanding gained in phase one. These codes identified features of the data that appeared interesting during phase one (Braun \& Clarke, 2006). The coding during this phase was data-driven, in that the codes were based on the responses found in the data rather than based on a specific, pre-existing theory. By coding the data in this way, the patterns that were present in the data were allowed to emerge and be analyzed. Once all the codes were selected the data was organized and collated based on the coding.

Phase three involves analyzing the coded data in an effort to identify themes across the data set. In this phase codes were sorted into potential themes, and compared again to start to determine how the codes can come together and form a theme. Themes were then reviewed and sorted to determine the relationship between the codes and themes which allows for the development of the main overarching theme and any subthemes that may have been found through this analysis. This led to phase four of the analysis, where the potential themes found in phase three were reviewed to determine if they are in fact themes or not. Some potential themes did not have enough data to support 
them as a theme. In other cases, some themes were so similar that they came together as a single theme. Conversely, one potential theme was too large and needed to be broken apart into two separate themes. The data that supported the themes needed to be cohesive and separate themes needed to be clearly differentiated (Braun \& Clarke, 2006, p. 20). There were two levels of analysis used in this phase. The first level involves reviewing the coded data within each theme to ensure that the data presents a coherent pattern. Then the second level of analysis is applied to the theme, which involved checking the theme against the data set as a whole, making sure that it accurately represented the data of the entire set (Braun \& Clarke, 2006, p. 21). Any inconsistencies in a theme were reviewed and the data was checked against the potential theme to see if there were simply data extracts that should not be included in the theme or if the theme itself is simply not working. In the case of certain data not working within the potential theme those troublesome data were then re-evaluated and moved to a more appropriate theme. Once both levels were completed, the themes and data created a thematic "map" of the data set as a whole, at which it was possible to move to phase five of the analysis (Braun \& Clarke, 2006, p. 21).

Phase five is the process in which the themes identified in phase four were named and defined for presentation. The data was used to "define and refine" (Braun \& Clarke, 2006, p. 22) the themes throughout the data set. The themes were defined and then tied together to give an overall analysis of the data set by reorganizing the data within each theme into a coherent and consistent account and then writing a detailed narrative to accompany each theme (Braun \& Clarke, 2006, p. 22). The data within each theme was used to work through the themes and present why the theme is relevant to the data and 
how it relates to any overarching themes that were present. It was also during phase five that any sub-themes were identified and discussed in the narrative if necessary. Subthemes are useful, especially if found in larger themes as they help further break down and explain each theme as it relates to the story that the data is telling. (Braun \& Clarke, 2006, p. 22). At the end of phase five, the themes were also given their final names and it is at that point that phase six began.

Phase six is when the report was produced to present the data analysis in a clear and concise way. In thematic analysis, the data needs to be presented in a way that tells the story of the data. The themes that were discovered and analyzed in the previous phases are presented, with examples from the data extracts to provide a coherent and logical account of the data (Braun \& Clarke, 2006, p. 23). The results section of this study will provide the themes as well as examples that exemplify each theme. Examples should be detailed and used to provide evidence of each theme and how the themes are present both within themselves and also how the themes support one another across the data set. The narrative also will, at this point, be tied in and make arguments in relation to the research questions of the study. In general, it is important for the report to give a clear narrative of the data and how it relates to the themes of the data set and how they relate to the research questions (Braun \& Clarke, 2006, p. 23).

It is also important to be aware of the potential pitfalls of thematic analysis. Most important is to ensure that the themes chosen are supported by the data within them and that there is significant data to represent a theme. It is also important to ensure that the data is being analyzed in a way that support and help support the themes identified rather than simply use the data as a theme itself (Braun \& Clarke, 2006, p. 25). Finally it is also 
necessary to make sure that the data and any analytical claims that are made about it are not mismatched. The data needs to support any claims made and be consistent with the data extracts that being used to identify and support themes. (Braun \& Clarke, 2006, p. 26).

Using Braun and Clarke's method of thematic analysis it is possible to analyze the data and identify themes that emerge from the participant's answers. By using this method, an in-depth look into each question will help formulate themes that appear and enable more insight into short-term worrisome events and the goals behind communicating that worry. 


\section{CHAPTER V}

\section{RESULTS}

Within this chapter, each research question will be applied to the corresponding data that was collected to learn more about short-term worrisome events. By using Braun and Clarke's (2006) six phases of thematic analysis, the data gathered was systematically organized based on themes that emerged from the data. These themes will be further analyzed along with their significance. Seventy participants, who are in close relationships, took the survey. While the majority of the participants described family members when relating to a short-term worrisome event, others also described situations that included friends, significant others, and finally the lowest number being a spouse. Spouse being the lowest number is not surprising considering forty-five of the seventy participants were under the age of thirty. The majority of the relationships, forty-three, in the survey were relationships that were over ten years old, which also follows along with thirty-six of the participants describing a short-term worrisome event that involved a family member.

\section{Research Question One}

After thematically analyzing the question in the study: Describe a short-term worrisome event you experienced involving someone you are close to (friend/family/significant other), this study sought to answer Research Question 1. 
RQ1: What events lead to short-term worry for participants in a close relationship?

Five themes emerged while evaluating the responses to the question of which events led to short-term worry. The five themes were (a) finances, (b) dangerous situation, (c) relationship status, (d) health, and (e) lack of communication. The frequency of these responses was (a) 4, (b) 7, (c) 9, (d) 33, and (e) 17 respectively.

The first theme, finances, emerged in the descriptions as an event that occurred that led to momentary concern over a person's monetary situation. Examples include losing a job, finding a job, or being taken advantage of financially. "When my daughter lost her job. I was worried as to what she would do if it kept her from finding another that she was qualified for" was one description a participant wrote to describe their short-term worry. Even though monetary issues tend to lead to long-term worry or rumination, it also can cause short-term worrisome situations when it has immediate impact and until the situation, such as a job loss, is resolved. While this situation could lead into rumination, trying to communicate that initial short-term worry can bring up different goals than rumination. \Another example of finances causing short-term worry is the worry of someone being taken advantage of financially, "My estranged brother divorced my sister-in-law. She did not have an attorney; it was finalized in another state, and was done very quickly. I was worried for her because my brother is a narcissist and had to have had a plan to make her think her settlement was satisfactory." The theme of finances has been studied on a large scale of worry: financial status was a listed source of worry in the Worry Domains Questionnaire as well (Tallis et al., 1992). While this study only 
identified financial short-term worry, previous literature shows there is a recurring link between finances and worry.

The second theme that emerged is short-term worry based on dangerous situations. A participant wrote "A time that I had short-term worry was when my mom was driving home from a super severe storm. I was worried about her safety driving through the storm. It was short-term because the storm was quick and then I no longer had to worry." Dangerous situations that occur have a combination of being short-term as well as evoking high emotions. Traveling conditions, being in a dangerous area, or natural disasters can lead to short-term worry, especially due to the fact that driving conditions could be hazardous and the weather is out of the person's scope of control. Reacting to these situations and expressing worry is different than other types of shortterm worry because it is not typically behavioral but more conditional, such as weather leading to bad driving conditions or a natural disaster causing a dangerous situation. Another participant also discussed a dangerous situation that caused them short-term worry: “Our daughter was traveling a normally 5 hour trip during a winter storm. When she left in the morning the sun was shining where she was so she was not aware of the conditions ahead of her. The interstate and many highways were closed. I was on the phone with her several times through out the day letting her know what the conditions were like down the road for her. After getting her to stop and wait it out for awhile she decided to continue shortly before it was about to get dark and she had several hours yet to travel. The 5 hour trip took her 12 hours." Similar to the previous example, this situation involved weather conditions that were out of the person's control. The participant responded by trying to gather as much information as possible and 
communicate that information to the person who they were worrying about in an effort to help the person and alleviate their need to worry.

Another theme that appeared frequently when participants were describing a short-term worrisome event revolved around health. This could be physical or mental health. As with financial issues, health is another concept that is related to rumination. People worry about eating healthier, working out, mental agility, and longevity. Worry about these things is more of an ongoing/constant in people's lives but sometimes events happen that threaten the immediate health of a person that makes others worry. For example, one participant recounted an event that caused short-term worry: "My wife was complaining of pains and her doctor ordered CT and Ultrasounds. I was worried because I wasn't sure what would be causing the pain and I know sometimes pain in the area she was experiencing it in could be cancers/ulcers and I was a little scared." This was a shortterm worrisome event because of the uncertainty related to what was actually wrong with his wife. Waiting for answers allowed time for the participant to worry about possible negative outcomes that would be confirmed or denied in a fixed amount of time, as opposed to ruminating about all future health issues that could happen. Another participant experienced short-term worry when a family member had experienced a medical emergency: "My mom had a stroke and my husband called the school while I was in class to tell me that she had managed to call an ambulance and was on the way to the hospital. I was worried about the extent of the damage to her brain." This type of traumatic health situation caused the participant to experience short-term worry. The participant indicated that they tried to gather as much information as possible to help alleviate their worry. Additionally, a sub-theme related to mental health emerged within 
the health related theme. While a person may worry about hereditary mental issues or age related mental decline, a different form of mental health event could cause short-term worry, such as low self-esteem or feelings of depression. "On my sister's 30th birthday, she was pretty down. My mom even forgot to call her and sent her card without a stamp, so it returned to us. My sister told me that it was the most important day of her life, though she hadn't told me that before so I had no idea. I was worried about her because she didn't seem to be doing well and she didn't feel appreciated." This is an example of a short-term worry, the participant was concerned about her sister in a specific situation, and felt worry because of this single event.

The fourth theme that became apparent was in regards to a change in relationship status. This refers to a person being concerned about breaking up with a significant other, losing a friend, and/or potentially having a family member stop talking to them. For example, "When talking to my close friend, their answers got short, and seemed distant. I became worried that they were upset with me, or that our relationship was going to change for the worse." This event led to short-term worry because of the uncertainty in the relationship status or worry that it was going to change due to the behavior of the person in a close relationship with the participant. Other responses within this theme of short-term worry related to changing of relationship status were related to the participant's behavior causing worry about impacting the relationship in a negative way such as breaking a necklace of someone he/she was in a close relationship with or being in the middle of two friends fighting and trying to keep both friendships.

Finally, the fifth theme identified was lack of communication. Lack of communication in a situation can cause short-term worry. For example: "When my sister 
turned 21 she went out at her campus with friends to celebrate. When we tried to call her that night to see if she was okay her phone was dead and we could not get a hold of her. It took several hours to get a hold of her and me and my parents were very worried." With easy access to instant communication, such as cell phones, the lack of communication is becoming a higher cause of worry. People expect to be able to reach anyone instantly and when that doesn't happen, negative thoughts can occur. The longer the attempted communication is not reciprocated, the more the person worries that something negative occurred.

Several types of events lead to short-term worry such as financial situations, dangerous situations, relationship status, health issues and lack of communication. The following section will discuss the ways in which the participants communicated their worry.

\section{Research Question Two}

Knowing the goals behind the expression of short-term worry people can identify better ways to react/respond to a short-term worrisome event. Research question two sought to determine how people reacted and communicated during a short-term worrisome event.

RQ2: What are the types of reactions/responses people employ to express his/her short-term worry?

All of the aforementioned short-term worrisome events led to participants determining whether or not to communicate their worry to the person that caused the worry or to someone else. The five themes that emerged from the data included (a) communicating worry, (b) controlling emotion, (c) emotional response, (d) gathering 
information, and (e) taking action. The frequency of each response was (a) 17, (b) 14, (c) 13, (d) 13, and (e) 13 respectively.

The first theme is communicating worry. This includes conveying the worry to the person that caused the worry. For example, "At times I voiced my concern in a concrete and clear way. Other times I became irate and projected this." The participant felt the need to talk to the person that caused the worry or to another person for various reasons such as alleviating the worry, change a behavior, or show concern for the person that caused the worry. The participant decided to address the event to help deal with the issue. Another example of this is "I cautioned her repeatedly to pay attention to her surroundings and to watch her feet while walking." This is a direct approach to addressing the short-term worry as opposed to other themes, such as gathering information and controlling emotion.

Another response to the short-term worrisome event is to control emotion. Controlling emotions was used in response to a few different short-term worrisome events, especially health, so the participant could help the person that was causing the worry or try to overcome the worry with positive thoughts. "I tried to remain calm, help Brian to gather information from the doctors, nurses etc. I was focusing on all the positives I could find." is an example of the participant trying to control their emotions to be more positive in the situation instead of letting his/her worry impact the situation. Another participant wrote, "Tried to just remain positive and hope for the best." Finally, a participant said, "My mom was worried herself. I did not communicate my worry to her, in order to keep a positive atmosphere." All of these responses imply that the participant 
had negative thoughts, but chose to instead to project positivity in the situation to help reduce the short-term worry in themselves and well as the subject.

The next theme discovered is having an emotional response. The worry-inducing event caused the participant to react in a more emotional way, such as: "First panicked and scared and then worried and I still continue to worry it will repeat itself." In this example, the participant experienced different emotions and let those emotions influence how he/she reacted to the event. Other indicators of an emotional response in from the participants included words such as "anxious", "panicked", "unhappy”, and "upset”. These types of emotional responses show how intense a short-term worrisome event can be, and the emotional toll, short-term worry can cause. Having an emotional response can help alleviate personal worry and some participants wrote that he/she hoped the emotional response would help change the behavior of the person that caused the shortterm worry.

Gathering information is another way participants responded to short-term worrisome events. The uncertainty of the event led participants to cope in different ways. Some called the person that caused the worry to find out more information, while others called people in their network. For example, "I watched the weather for her and kept calling on her and checking on her." The participant reacted to the event by finding out as much information as possible to help alleviate the worry and/or assist the person that was causing the worry. Another example of gathering information was, "I responded by trying to call everyone and everywhere I had a number to that might possibly know of his whereabouts." This participant was trying to use find out information about the person through other relationships to help alleviate worry. 
Close to that response is the last theme that appeared in the responses, and that is taking action. In response to his/her worry, participants did things such as "Sending cards to my friend, sending flowers, calling, messaging" to address his/her worry. Many of these responses were to show concern for the person that was causing the worry or to alleviate the worry. By focusing on positive action, the participant could help resolve some of the short-term worry he/she was feeling.

People respond in different ways during short-term worrisome events. There were five general response found in this study; (a) communicating worry, (b) controlling emotion, (c) emotional response, (d) gathering information, and (e) taking action. The next section will address the goals of communicating during short-term worrisome events.

\section{Research Question Three}

The short-term worrisome events and responses led to an important issue: the goals of communicating or not communicating short-term worry. By using the six phase thematic analysis, six goals emerged from the data: (a) alleviate personal worry, (b) show support for other, (c) change behavior, (d) not address the worry, (e) look good, and (f) validate the relationship. The frequency of each response was (a) 18, (b) 24, (c) 12, (d) 2 , (e) 13 , and (f) 1 respectively.

RQ3: What, if any, types of relational goals do participants employ when deciding whether and how to express their short-term worry?

The first goal is to alleviate the worry of the person who experienced short-term worry, "I wanted to express my feelings to a third party and see what they thought about the situation. I guess I just wanted someone to tell me everything will be okay." This 
shows a self-focused interest in communicating worry; to make him/her feel better and/or receive positive confirmation from another person. Another person wrote "peace of mind." In short-term worrisome events, the participant might be the only one experiencing the worry and therefore might look to others to help alleviate that worry or validate his/her feelings. If he/she are in a group setting and see no one else is worried, it may relieve some of his/her short-term worry. A support group of people telling the person that everything will be alright is another way that could help convince the person that his/her worry is unfounded.

The second goal identified is to show support for the other person in the event. "I was showing obvious care in her time of need." This one example of the participant showing his/her concern for the other person. Instead of alleviating his/her worry, he/she chose to try to show the other person he/she cared. This is almost opposite in regards to the first theme of alleviating personal worry, and instead trying to alleviate worry for the person that is causing the short-term worry. "I was trying to make sure that my sister felt better about the day and that she felt loved and appreciated. I was also hoping that my mom would call and apologize for missing the day." In this example the participant shows concern. The majority of this theme was based on a participant describing an event with a family member with only a couple friends and significant others being described. Two of the themes, looking good and validating the relationship, may not be as relevant to family relationships because of the stability of family. Family is a typically more longterm, people that have been in a person's life since he/she was growing up so the need to look good does not apply as much as well as validating the relationship. No matter what happens, a sister is still a sister; whereas, a friend could no longer be a friend. 
The third goal is to change the behavior of the person in the short-term worry event. This is when a behavior has caused the short-term worry and the participant hopes that by communicating his/her worry, the person that caused the worry will change his/her behavior. One participant wrote, "We were trying to tell her to be more responsible when going out drinking." While this also shows concern for the other person, the primary goal is to change the behavior that caused the worry. Interestingly, a high majority of this goal is from participants describing a relationship with a friend. Six out of the seventeen friend relationship examples focused on changing behavior.

Not showing worry is the fourth goal in short-term worrisome situations because it could harm the situation/relationship by adding to the worry or make the person that is causing the worry to worry more. One participant wrote, "To keep him somewhat calm, and make him feel comfortable, he was extremely worried so I tried to hide my worry from him and remain focused on the positive result the doctor was trying to achieve for him." Instead of bringing more conflict/worry into the situation, the participant decided to not show worry. However, sometimes this had a negative impact on the worrier, for example: "By keeping it to myself, it bottled up and caused me to over think every story he would tell me. I wasn't sure if it was the truth and it made me paranoid." Not only was the worry not addressed, it made the participant continue to worry and according the participant "it caused unnecessary tension" to the relationship.

The fifth goal is to make the worrier look good. "I felt like I should make every attempt to contact her so she would not think I was negligent or insensitive." The worrier wanted to communicate his/her worry to make him/her appear better. Not "negligent or insensitive", the worrier chose to communicate worry for reasons other than alleviating 
the person's worry or show support for the other person. This goal was not as prominent as the other goals but was interesting to note since the goal described by the participant was so different from the other responses. This goal was more focused on the worrier's image instead of the person that caused the worry. While alleviating person worry is also self-focused, this goal is more directed at keeping up an appearance and not for any emotional release.

The sixth and final goal was to validate the relationship. "I was trying to show my friend that I was not going to lie to him, and that he would see that I wasn't trying to take sides in the fight between him and our other friend" is an example of the worrier trying to validate his/her relationship. He/she wanted to communicate that he/she is not taking sides and to keep the relationship. This last goal was only mentioned once in all of the responses, but was interesting because it was more relationship focused instead of being self-focused or focused on the other person involved.

Research question three explored the goals of individuals during short-term worrisome events. There were six goals identified in the study; (a) alleviate personal worry, (b) show support for other, (c) change behavior, (d) not address the worry, (e) look good, and (f) validate the relationship. The next section will address the outcome the participants experienced.

\section{Research Question Four}

RQ4: How, if at all, do participants feel like their particular responses to the worrisome event help achieve their goals?

The last question this study explored was whether participants felt like their communicative response helped alleviate their worry. The majority of participants $(n=$ 
44) responded that they thought that communicating their worry helped as opposed to 26 who did not think it helped alleviate their worry. The study yielded mixed results on the reactions to the communicative responses to the short-term worrisome event. While the majority of the worriers thought that they received a positive reaction to them communicating their worry, such as, "For the most part, they were receptive and understanding," some had a negative response, "He thought my reaction was not warranted.” It also helped prevent future short-term worrisome situations for occurring after the participant communicated their worry. For example, "Relieved that he will respond in a timelier manner. He now understands why I feel the way I do."

The impact of the short-term event on the relationship of the participant and the person he/she described in the event also had varied results. Some participants claimed the participants' response to the short-term worrisome event had no impact on the relationship while others had negative and positive impacts. One example of a positive impact was that the response did "improve our relationship within the family; we converse and get along better than we used to." This example shows that by communicating worry, it can lead to changes in a relationship for the better and improve communication. However, there were also reports of negative impacts of communicating short-term worry. "It put a temporary strain on our relationship, but we eventually became very close again. However, we no longer speak for reasons unrelated to this event." is an example of communicating worry leading to a negative result. While there were a higher number of positive outcomes than negative, further examination behind how the worry was communicated in relationship to the impact is needed. 
Using thematic analysis to analyze the data this study has addressed the four research questions about what short-term worrisome events look like and how the participants reacted and their communicative goals and the effectiveness of the their communication of that worry. This chapter lays out the foundation of short-term worrisome events and how it's communicated. By creating themes a framework has been developed that can be applied to theories in the future. This study has also shown insight into the importance of short-term worry and why further research is necessary. 


\section{CHAPTER VI}

\section{DISCUSSION}

Results from the previous chapter validate the importance of short-term worry in a communication context. People do experience this type of worry and try to communicate short-term worry with a variety of goals in mind. Identifying those goals and being able to cognitively restructure his/her worry before expressing it to the worrier to align with those goals, can make the communicated message more effective and help meet his/her goals. These short-term worrisome events, even though short in time, can have long lasting effects on close relationships, even to the point of threatening the relationship as a whole. It is important to communicate the worry in a way that will achieve the worrier's goal as well as improve the relationship.

The purpose of this study was to gain a better understanding of what short-term worrisome events looked liked, how people communicated their worry, the goals behind their communication, and whether or not their communicated message helped achieve their goals. By having participants describe a short-term worrisome event, thematic analysis was used to see if there were common types of short-term worrisome events. This study identified five common events: finances, dangerous situation, relationship status, health, and lack of communication. Based on previous literature on worry, some of the themes were to be expected. The Worry Domains Questionnaire (Tallis et al., 1992) 
had two similar results, relationships and financial status, to what this study produced. Whether long-term or short-term, people worry about finances and their relationships. Health is another constant when discussing worry. Earlier research was based on mental health, and in this study participants were also worried about the health of others.

The second research question addressed how the participants communicated their worry. While some chose to communicate their worry directly to the person causing the worry, others found different methods, such as control emotion, have an emotional response, gather information, or take action. The dichotomy of controlling emotion versus having an emotional response to a short-term worrisome event would be interesting to further explore. Examining what goals people have when regulating their emotion and its results, could help people change the way they communicate worry in order to succeed in their goal. Emotion regulation has not been directly studied with worry but this study has discovered that people apply it when deciding how to communicate worry. Gathering information is another way people communicate their worry. Information seeking tendencies has been related to worry along with uncertainty (Smith \& Ellsworth, 1985). This need to seek information due to the uncertainty of the short-term worrisome event can stem from different aspects of uncertainty: uncertainty of relationship status, uncertainty of well-being, and uncertainty of feelings of the person causing the worry. As stated in the literature, if the worry is not relieved, it could create more worry (Knobloch \& Soloman, 2005) and could eventually lead into a more ruminative worry or more extreme information-seeking tendencies.

Research question three had the participants identify the goals they had behind communicating their worry: alleviating personal worry, showing concern for other, 
change behavior, not address the worry, look good, and validate the relationship. Samp and Soloman (1998) also identified similar goals to communicating in problematic events that could be applied to future research. The last research question asked the participants to discuss whether or not communicating their worry helped achieve their goals. Overall, the results were positive that communicating worry helped achieve the worrier's goal. It was interesting to note that in some cases, communicating the worry put a strain on the relationship.

\section{Theoretical Implications}

While this study did not include a theoretical framework into the study itself because of the newness of the subject, after this initial study, there are a few theories that would make an interesting application to short-term worry. Appraisal and regulation theory are two theories that have strong connections to short-term worrisome events. Participants identified that during the short-term worrisome event, they did different things to help regulate their worry, such as information seeking or trying to suppress their emotion. They would check the weather or road conditions as well as call other close relationships for information. Others incorporated suppression, concealing their emotions in order to not create more worry in the person that caused it, especially during healthrelated short-term events. By applying appraisal theory, a person may overreact to a short-term worrisome event and then have to use reappraise the situation (Mancillia et al. 2009). During a short-term worrisome event, a person may overreact but then reevaluate the situation at a later time. This was seen in the goal to alleviate personal worry and express emotion. A person may also look to others to see how worried he/she should be a reappraise the situation and their feelings towards it. 
Another theory to use when examining short-term worrisome events is expectation violation theory. This study did not address the participants' expectations of the person even though it was implied that they experienced short-term worry because the person violated their expectations in some way. The person that caused the worry did something unintentional or intentional that was different from the norm, causing a person to worry and become more emotional (Burgoon \& Hale, 1988). By examining expectations in close relationships, deeper insight into what causes short-term worry can be gained.

Based on the criteria by Mancillias et al. (2009) worry is a secondary emotion. Worry is learned from cultural and societal norms and it is expressed by using primary emotions. It can be comprised of anger, fear, and sadness. Some short-term worry is based on social cues and the modern ability to reach anyone at any given time. Looking at how people communicate worry, especially on a short-term basis when emotions are high can lead to a stronger understanding of emotions and emotion expression. Emotional expression in relationship to worry has been defined as the ability or inability to control negative feelings (Ruscio \& Barkovec, 2004). The results showed that sometimes the goal was to emotionally express worry and alleviate the worry of the worrier, while other times it was to not show emotion. The goal to not show emotion may be to keep the person that caused the worry calm in a short-term worrisome situation. Active worry was seen as being more positive (Davey, 1993) than rumination. Short-term worry situations led to more action being taken helped mitigate the worry and overall had a more positive result that not addressing the worry. So while the term "worry" may be seen as negative, positive results can occur. The results showed that in some cases it strengthened 
relationship and helped people communicate more. The next section will examine the practical implications of this study.

\section{Practical Implications}

The practical side to this study is that it allows for self-reflection on individual instances where a person could choose a more effective way to communicate their worry to match their goals. Participants in the study reflected on whether or not they felt that their communication of their short-term worry helped achieve their goal. While the majority of the participants felt that it did help achieve their goal, it did not always have a positive impact on the relationship, in some cases, putting an extra strain on the relationship. Awareness of how a person communicates emotional stress, such as shortterm worry, can help people restructure how they present their worry and have more positive impacts on relationships. This study hopes to bring more awareness of short-term worry and how people communicate their worry. By identifying the goals behind the communication, further reflection and message restructuring can help people communicate more effectively. By cognitively identifying the worrier's primary goal versus the secondary goals; they can create a message that will lend to the success of the primary goal. The goals-plans-actions model discusses how goals influence the nature of interpersonal communication and use a three step sequence to communicate goals (Dillard, 2004). By applying this method when faced with a short-term worrisome situation, it could help structure messages to be more effective. When a short-term worrisome event occurs, the worrier could identify the goals they hope to achieve, plan how they intend to communicate those goals, and decide to how/when to communicate the worry that was caused with their goals in mind. 


\section{Future Research}

As stated, this study is a foundation into examining short-term worry and communicative responses to short-term worry. Samp and Solomon (1998) examined communicative responses in close relationships to problematic events. Their findings indicated that there are multiple goals when communicating a response to a problematic event (Samp \& Solomon, 1998). However, certain message goals were more important to respondents of the study than other goals; "accepting fault" was the goal with the highest response while "avoiding addressing the event" was the least prevalent goal of the respondents (Samp \& Solomon, 1998). These concepts were seen in short-term worrisome events as well, such as avoiding addressing the event. Further development with these ideas could help propel the study of short-term worry forward. Using this study along with Samp and Solomon's work could gain more insight into short-term worry.

This study also did not look at the person who caused the worry to find out if it was intentional or not. It would be interesting to look at people who use short-term worry to control a situation or relationship. They may know the person they are in a close relationship has a tendency to worry so they purposely create these situations for their advantage in the relationship. A person could intentionally cause short-term worry to get a significant other to express their feelings, make them forget a fight, or change the worrier's behavior.

Emotional expression could also be a form of manipulation in a short-term worrisome event. Instead of calmly discussing the worry, a person could chose to express their worry with stronger emotions to achieve their goal. Being overtly sad or angry in the 
situation could help achieve compliance quicker than a calm discussion. If the person that caused the worry feels guilty about causing a strong emotion in the other person, it may be easier for the worrier to achieve their goals. It could also make the worrier look better because they were so emotional about the situation. If they overreact in the eyes of the person that caused the worry, it could have a negative impact on the worriers goals and the relationship.

The person who experienced the worry could also use impression management when communicating their worry. Impression management is process of trying to control others' perceptions (Leary, 1995). They could be communicating worry to make themselves look good in the situation or to try to be the "caring" person or the person more invested in the relationship. Using a short-term worrisome event to shape perceptions or manipulate the relationship could be another area to examine.

While furthering the validity of what short-term worrisome events and the goals behind communicating that worry, there are other directions this study laid the foundation. This study focused on close relationships because of the stronger emotional link and potentially higher frequency of short-term worrisome situations; however, applying this knowledge to other types of relationships would be beneficial. Short-term worrisome events occur in other areas of people's lives, such as social situations and at work. People may experience short-term worry when out running errands and getting a flat tire, or their credit card being declined. At work, if your boss wishes to speak to you privately, it can cause short-term worry due to the uncertainty of the situation. How people cope in these situations has yet to be examined as well as how they communicate this worry. 


\section{Limitations}

This study also had some limitations. It was an online survey that had seventy participants. While that allowed for a thematic analysis and a basic understanding of short-term worry, further exploration into the area could help create a better understanding of short-term worry and its importance. Talking to participants face-toface would have allowed for further development of ideas instead of only being able to

glean information from the text written by the participants. The participants self-reported on events they perceived to have caused short-term worry and a retrospective analysis of how they responded and the goals. These events and communicated responses may have been altered to reflect the person describing the event in a more positive light. Also, while the age range was broad, the diversity of ethnics was limited as well as having a higher ratio of females to males. The study is a good starting point for a closer look into short-term worry in a more diverse spectrum.

\section{Conclusion}

While worry is not new, worry in a short-term context is and this research is just the start to fully understanding how people communicate their worry and the goals they hope to achieve by communicating their worry in short-term settings. Expressing shortterm worry can be difficult and communicating it in an effective manner, even harder. Learning how individuals respond to short-term worrisome events and their goals can help lead to further understanding of short-term worry and make people more cognitive of how their responses are being received.

The purpose of this study was to gain a better understanding of short-term worrisome events. Virtually unstudied, this opens options for further research into short- 
term worry and also demonstrated the validity of worry in a short-term context. It looked at broader areas of worry and transformed it into a new area to explore when examining how people communicate worry. Overall this study helped define what short-term worrisome events are, different themes of the communicative responses, and goals behind communicating worry in short-term worrisome events. 


\section{REFERENCES}

Afifi, W. A., \& Metts, S. (1998). Characteristics and consequences of expectation violations in close relationships. Journal of Social and Personal Relationships, 15, 365-392. doi: 10.1177/0265407598153004.

Aune, Krystyna. (2006). Relational Uncertainty, Emotional Commitment, and Emotion Expression in Romantic Relationships. Conference Papers -- International Communication Association. 1-24.

Booth-Butterfield, M., \& Kennedy-Lightsey, C. (2011). Responses to jealousy situations that evoke uncertainty in married and dating relationships. Communication Quarterly 59-2. doi: 10.1080/01463373.2011.563443.

Borkovec, T. D., Robinson, E., Pruzinsky, T., \& Dupree, J. A. (1983). Preliminary exploration of worry: Some characteristics and processes. Behaviour Research and Therapy, 23, 481-482. doi: 10.1016/0005-7967(83)90121-3.

Burgoon, J. K., \& Jones, S. B. (1976). Toward a theory of personal space expectations and their violations. Human Communication Research, 2, 131-146.

Burgoon, J. K., \& Hale, J. L. (1988). Nonverbal expectancy violations: Model elaboration and application to immediacy behaviors. Communications Monographs. 55. 5879. doi: 10.1080/03637758809376158. 
Burgoon, J.K. (1995). Cross-cultural and intercultural applications of expectancy violations theory. In R. L. Wiseman (Ed.), Intercultural communication theory: International and intercultural communication annual (Vol. 19, pp. 194214).

Brashers, D., Neidig, J., Haas, S. M., Dobbs, L. K., Cardillo, L. W., \& Russell, J. A. (2000). Communication in the management of uncertainty: The case of persons living with HIVor AIDS. Communication Monographs, 67. 63-84. doi: 10.1111/j.1460-2466.2001.tb02892.x.

Braun, V. and Clarke, V. (2006). Using thematic analysis in psychology. Qualitative Research in Psychology, 3 (2). 77-101. doi: 10.1191/1478088706qp063oa.

Clark, M. S., \& Finkel, E. J. (2005). Willingness to express emotion: The impact of relationshiptype, communal orientation, and their interaction. Personal Relationships, 12, 169-180. doi: 10.1111/j.1350-4126.2005.00109.x.

Cheng, Yin-Hui, Kuan, Fu-Yung, Li, Chun-I, Ken, Yun. (2010). A Comparison Between the Effect of Emotional Certainty and Uncertainty on Coping Strategies. Social Behavior and Personality, 38, 53-60.

Chiles, B., \& Roloff, M. (2014). Apologies, expectations, and violations: An analysis of confirmed and disconfirmed expectations for responses to apologies.

Communication Reports, 27 (2), 65-77. doi: 10.1080/08934215.2014.890735.

Dainton, M. \& Aylor, B. (2001). A relational uncertainty analysis of jealousy, trust, and maintenance in long-distance versus geographically close relationships. Communication Quarterly. 49-2. doi: 10.1080/01463370109385624.

Davey G. C. (1993). A comparison of three worry questionnaires. Behavioral Research Therapy, 28, 51-56. doi: 10.1016/0005-7967(93)90042-S. 
Davey, L. (1993). A comparison of three cognitive appraisal strategies: The role of threat in devaluation of problem-focused coping. Personality and Individual Differences, 14, 535-546. doi: 10.1016/0191-8869(93)90146-T.

David, D, \& Stefan, S. (2013). The Functions of Worry in Uncontrollable Situations Perceived Effects of Worry and the Feeling of Being in Control. Cognition and Emotion, 27. 521-529

Dillard, J.P. (2004). The goals-plans-action model of interpersonal influence. Perspectives of persuasion, social influence, and compliance gaining. Boston, MA: Pearson Education. (p 185-206).

Eagly, A.H., \& Chaiken, S., (1995). The Psychology of Attitudes. Psychology \& Marketing, 5, 459-466.

Goring, H., \& Papageorgiou, C. (2008). Rumination and worry: factor analysis of selfreport measures in depressed participants. Cognitive Therapy and Research, 32, 554-566.

Gregory, R. (1997). The Oxford companion to the mind. Oxford: Oxford University Press.Gross, J. J. (1998). Antecedent- and response-focused emotion regulation. Journal of Personality and Social Psychology, 74, 224-237.

Gross, James. (1998). The emerging field of emotion regulation: An integrative review. Review of General Psychology, Vol 2(3). 271-299. doi: dx.doi.org/10.1037/10892680.2.3.271.

Jang, Su Ahn, Yoo, Jina H., Tian, Yan. (2011) Attachment, Relational Uncertainty, Communication Efficacy and Avoidance Following Events that Increase 
Uncertainty in Close Relationships. Human Communication, Vol. 14 Issue 3. 205-219

Johnston, A. C., and Warkentin, M. (2010). "Fear Appeals and Information Security Behaviors: An Empirical Study," MIS Quarterly (34:1), pp. 549-566.

Kelly, W \& Paolini, L. (2014). The Relationship between Worry and Family Functioning Among Young Adults. Individual Differences Research, 12, 1, 31-37.

Knobloch, L. K., \& Solomon, D. H., (2005). Relational uncertainty and relational information processing: Questions without answers? Communication Research, 32, 249-288.doi: 10.1177/0093650205275384.

Leary, M. R. (1995). Self-presentation: Impression management and interpersonal behavior. Madison, WI: W. C. B. Brown \& Benchmark.

Lindlof, T \& Taylor, B. (2002). Qualitative Communication Research Methods. Sage Publications. 208-227.

Maguire, K. C. (2007). "Will it ever end?": A (re)examination of uncertainty in college student long-distance dating relationships. Communication Quarterly, 55, 415432. doi: 10.1080/01463370701658002.

Mancillias, W., Wilmot, W., \& Metts, S. (2009). You, me, and us (Chapter 7). Boston, MA: Pearson.

Matthews A. (1990) Why worry? The cognitive function of anxiety. Behavioral Research Therapy, 28, 455-468. doi: 10.1016/0005-7967(90)90132-3.

McCaul KD, Goetz P. (2008). Worry. Health behavior constructs: Theory measurement, and research..http://dccps.cancer.gov/brp/constructs/worry/index.html. 
Metts, S., \& Planalp, S. (2002). Emotional communication. In M. Knapp \& J. Daly (Eds.) Handbook of interpersonal communication, 2, p. 339-373. Thousand Oaks, CA: Sage Publications.

Meyer, T.J., Miller, M.L., Metzger, R.L., Borkovec, T. (1990). Development and validation of penn state worry questionnaire. Behaviour Research and Therapy 28-6. 487-495.doi: 10.1016/0005-7967(90)90135-6.

Papageorgiou, C. and Wells, A. (1999), Process and meta-cognitive dimensions of depressive and anxious thoughts and relationships with emotional intensity. Clin. Psychololgy \& Psychotherapy 6. 156-162. doi: 10.1002/(SICI)10990879(199905)6:2<156::AID-CPP196>3.0.CO;2-A.

Papageorgiou, C. and Wells, A. (2003). Frontmatter, in Depressive Rumination: Nature, Theory and Treatment, John Wiley \& Sons Ltd, Chichester, UK

Parkinson, B \& Simons, G (2012). Worry Spreads: Interpersonal transfer of problemrelated anxiety. Cognition and Emotion, 26, 462-479. University of Oxford, Oxford, U.K. doi: 10.1080/02699931.2011.651101.

Pennebaker, J. W. (1997). Writing about emotional experiences as a therapeutic process. Psychological Science, 8, 162-166. doi: 10.1111/j.1467-9280.1997.tb00403.x.

Planalp, S., Metts, S., \& Tracy, S. J. (2009). The social matrix of emotion expression and regulation. SAGE handbook of communication science. Newbury Park, CA: Sage.

Reisenzein, R., \& Spielhofer, C. (1994). Subjectively salient dimensions of emotional appraisal. Motivation and Emotion, 18, 31-77. doi: 10.1007/BF02252474.

Reolofs, J., Huiers, M., Peeters, F., Arntz, A., \& van Os, J. (2008). Rumination and worrying as possible mediators in the relation between neuroticism and symptoms 
of depression and anxiety in clinically depressed individuals. Behavior Research and Therapy, 46, 1283-1289. doi: 10.1016/j.brat.2008.10.002.

Richards, J. M., \& Gross, J. J. (2000). Emotion regulation and memory. Journal ofPersonality and Social Psychology, 79, 410-424.

Ruscio, A. M., \& Borkovec, T. D. (2004). Experience and appraisal of worry among high worriers with and without generalized anxiety disorder. Behaviour Research and Therapy, 42, 1469-1482.doi: 10.1016/j.brat.2003.10.007.

Samp, J \& Solomon, D (1998). Communicative responses to problematic events in close relationships I: the variety and facets of goals. Communication Research, 15, 66.

Samp, J \& Solomon, D (1999). Communicative responses to problematic events in close relationships II: the influence of five facets of goals on message features. Communication Research, 26, 193. doi: 10.1177/009365098025001003.

Smith, C. A., \& Ellsworth, P. C. (1985). Patterns of cognitive appraisal in Emotion. Journal of Personality and Social Psychology, 48, 813-838. doi: dx.doi.org/10.1037/0022-3514.48.4.813.

Stober, J. \& Muijs, M. (2001). Patterns of situational appraisal in experiences of worry and anxiety. Anxiety, Stress \& Coping; (14) 4, 367-391. doi: 10.1080/10615800108248362.

Tallis, F., Eyesenck, M., \& Matthews, A. (1992). A questionnaire for the measurement of nonpathological worry. Personality and Individual Differences, 13, 161-68.

Taylor, S \& Bogdan, R (1984). Introduction to qualitative research methods. WileyInterscience Publications. 125-145 
Wegner, D. M. (1992). You can't always think what you want. In M. P. Zanna (Ed.), Advances in experimental social psychology (Vol. 25, pp. 193-224). New York: Academic Press.

Wright, C., \& Roloff, M. (2015). You should just know why I'm upset: Expectancy Violation Theory and the influence of mind reading expectations (MRE) on responses to relational problems. Communication Research Reports, 32 (1), 1019.doi: $10.1080 / 08824096.2014 .989969$.

Yun, Doshik. (2005). Effects of Expectation Violation and Validation Process on Message Processing Modes. Human Communication 10, 4 523-535. 


\section{APPENDIX A}

\section{SURVEY QUESTIONNAIRE}

Dear Participants, I am a graduate student at the School of Communication at Illinois State University. I am conducting a research study to explore worry in a communication context. The survey consists of demographic questions and open ended questions that will take approximately 10 to 15 minutes to complete. The open ended questions will ask the participant to describe an event in which you were worried and how that worry was expressed. Your results will be analyzed for use in a Master's Thesis. The committee chair is Dr. Lance Lippert of the School of Communication faculty at Illinois State University. You must be at least18 years old to participate in this study. The survey is completely voluntary and anonymous. You will not be penalized if you choose to withdraw from the survey at any time with no risk or penalty to yourself. Although there may be no direct benefit to you, the possible benefit of your participation is future understanding of how worry is used and the effects of expressing worry in different ways. If you have any questions regarding this survey or your participation in this study, you may contact the researcher via e-mail: psteska@ilstu.edu (Pamela Steskal). Thank you for your participation in this study. If you have any questions about your rights as a subject/participant in this research, or if you feel you have been placed at risk, you can contact the Research Ethics \& Compliance Office at Illinois State University at (309) 
438-2529. I have read and understand the description and purpose of the study and I hereby give my consent to participate.

1. Describe a short-term worrisome event you experienced involving someone you are close to (friend/family/significant other).

2. Who is involved?

3. What is your relationship with the individual?

4. How long have you been in relationship? (drop down)
a. Less than a year
1-3 years
3-10 years $10+$ years

5. What was your response?

6. What were you trying to achieve?

7. Do you feel like your response helped you achieve your goal?

8. How worried were you (could be drop down)
a. Not Worried Somewhat Worried
Very Worried

9. What was the individual's reaction or response?

10. What did this do to the relationship?

11. How did the exchange make you feel?

12. How did it deal with the worry?

13. What did it do to your relationship?

Demographic questions

1. Sex: Male Female

2. Age: (years) 
3. Ethnicity:

Black/Non-hispanic

White/Non-hispanic

Hispanic
Asian or Pacific Islander

American Indian or Alaskan Native

Other 


\title{
APPENDIX B RECRUITMENT FORM
}

\begin{abstract}
A Study of Expressing Worry
I am a graduate student at the School of Communication at Illinois State University. I am conducting a research study to explore worry in a communication context. You are invited to participate in research that examines situations in which worry is evoked, how it is expressed, and the goals of expressing worry. Participation in this study is completely voluntary and anonymous. The survey will take approximately 10 to 15 minutes to complete. If you are interested in participating in the study and you are at least 18 years of age or older, follow the link below to access the electronic questionnaire at SelectSurvey.
\end{abstract}

http://20.selectsurvey.net/pamelasteskal/TakeSurvey.aspx?SurveyID=p2KH4m6

Thank you for your participation,

Pamela Steskal 